ARTICLE

\title{
Heterogeneous reduction of carbon dioxide by hydride-terminated silicon nanocrystals
}

Wei Sun ${ }^{1, \star}$, Chenxi Qian ${ }^{1, \star}$, Le He ${ }^{1,2}$, Kulbir Kaur Ghuman ${ }^{3}$, Annabelle P.Y. Wong ${ }^{1}$, Jia Jia ${ }^{1,3}$, Abdinoor A. Jelle ${ }^{1,3}$, Paul G. O'Brien ${ }^{4}$, Laura M. Reyes ${ }^{1}$, Thomas E. Wood ${ }^{4}$, Amr S. Helmy ${ }^{5}$, Charles A. Mims ${ }^{4}$, Chandra Veer Singh 3,6 $\&$ Geoffrey A. Ozin ${ }^{1}$

Silicon constitutes $28 \%$ of the earth's mass. Its high abundance, lack of toxicity and low cost coupled with its electrical and optical properties, make silicon unique among the semiconductors for converting sunlight into electricity. In the quest for semiconductors that can make chemicals and fuels from sunlight and carbon dioxide, unfortunately the best performers are invariably made from rare and expensive elements. Here we report the observation that hydride-terminated silicon nanocrystals with average diameter $3.5 \mathrm{~nm}$, denoted ncSi:H, can function as a single component heterogeneous reducing agent for converting gaseous carbon dioxide selectively to carbon monoxide, at a rate of hundreds of $\mu \mathrm{mol} \mathrm{h}{ }^{-1} \mathrm{~g}^{-1}$. The large surface area, broadband visible to near infrared light harvesting and reducing power of $\mathrm{SiH}$ surface sites of $\mathrm{ncSi:H}$, together play key roles in this conversion. Making use of the reducing power of nanostructured hydrides towards gaseous carbon dioxide is a conceptually distinct and commercially interesting strategy for making fuels directly from sunlight.

\footnotetext{
${ }^{1}$ Department of Chemistry, Solar Fuels Research Cluster, University of Toronto, 80 St George Street, Toronto, Ontario, Canada M5S $3 \mathrm{H6} .{ }^{2}$ Institute of Functional Nano and Soft Materials (FUNSOM), Jiangsu Key Laboratory of Carbon-based Functional Materials and Devices, and Collaborative Innovation Center of Suzhou Nano Science and Technology, Soochow University, Suzhou, Jiangsu 215123, China. ${ }^{3}$ Department of Materials Science and Engineering, University of Toronto, 184 College Street, Suite 140, Toronto, Ontario, Canada M5S 3E4. ${ }^{4}$ Department of Chemical Engineering and Applied Chemistry, Solar Fuels Research Cluster, University of Toronto, 200 College Street, Suite 103, Toronto, Ontario, Canada M5S 3E4. ${ }^{5}$ The Edward S. Rogers Sr Department of Electrical and Computer Engineering, University of Toronto, 10 King's College Road, Toronto, Ontario, Canada M5S 3G4. ${ }^{6}$ The Department of Mechanical and Industrial Engineering, University of Toronto, 5 King's College Road, Toronto, Ontario, Canada M5S 3G8. * These authors contributed equally to this work. Correspondence and requests for materials should be addressed to L.H. (email: lehe@suda.edu.cn) or to G.A.O. (email: gozin@chem.utoronto.ca).
} 
O wing to its unique electrical, optical and thermal properties as well as its high earth abundance, silicon materials have found pervasive applications in energy conversion and storage. Silicon nanostructures with large surface areas and widely tunable chemical and physical properties are of special interest in diverse areas, including solar cells ${ }^{1-3}$, lithium-ion batteries ${ }^{4-7}$, thermoelectrics ${ }^{8,9}$ and photocatalysis ${ }^{10}$.

Recently, the field of solar fuels has emerged that aims to harvest, convert and store solar energy in the form of chemical energy $^{11}$. Owing to silicon's low cost and lack of toxicity, and small electronic band gap for near-infrared to visible light absorption, it is scientifically and technologically interesting to introduce silicon nanostructures into different types of solar-tochemical energy platforms. Silicon nanowires, for example, have been employed as electrodes for photoelectrochemical generation of $\mathrm{H}_{2}$ from $\mathrm{H}_{2} \mathrm{O}$, photodegradation of dyes, and as anodes in lithium ion batteries ${ }^{4,6,12-14}$. Porous silicon and silicon nanocrystals are showing promise for bio-medical and optoelectronic applications ${ }^{15,16}$.

In the context of $\mathrm{CO}_{2}$ reduction, it is noteworthy that organo silyl hydrides are well known for their ability to homogeneously reduce $\mathrm{CO}_{2}$. In stark contrast, hydride functionalized silicon nanocrystals have not previously been imagined as a reagent for the heterogeneous gas-phase reduction of $\mathrm{CO}_{2}$. To amplify on the former, the first step in the solution phase hydrosilation of $\mathrm{SiH}$ bonds in molecular silyl hydrides with $\mathrm{CO}_{2}$ has been reported to involve the formation of a formoxysilane $\mathrm{SiOCHO}$ group containing a $\mathrm{SiO}$ bond ${ }^{17}$. This insertion reaction is usually enabled using a transition metal or main group homogenous co-catalyst under high temperature and/or pressure conditions. In the case of molecular silyl dihydrides, hydrosilation of $\mathrm{CO}_{2}$ has been shown to form di-formoxysilane $\mathrm{Si}(\mathrm{OCHO})_{2}$ groups ${ }^{18}$. These formoxysilanes as well as silylacetal groups have been implicated in the reduction of $\mathrm{CO}_{2}$ to $\mathrm{CH}_{3} \mathrm{OH}$ and $\mathrm{CH}_{4}$ (refs 17,19-22). There was also a report that by using aqueous $\mathrm{Na}_{2} \mathrm{CO}_{3}$ in the presence of silicon quantum dots, both $\mathrm{HCHO}$ and $\mathrm{HCO}_{2} \mathrm{H}$ were detected using the Nash reagent ${ }^{23}$.

Herein we document the ability of surface hydride functionalized silicon nanocrystals, denoted $\mathrm{ncSi}: \mathrm{H}$, to selectively reduce gaseous $\mathrm{CO}_{2}$ to $\mathrm{CO}$ using the heat and light from the sun. Compared with this gas-phase heterogeneous reduction of $\mathrm{CO}_{2}$ the aforementioned liquid-phase homogenous hydrogenation of $\mathrm{CO}_{2}$ has several disadvantages that include: (i) solubility, diffusion and temperature limitations of $\mathrm{CO}_{2}$ in the liquid-phase, (ii) requirement of a catalyst, (iii) recovery and regeneration of catalysts from the liquid-phase and (iv) the scalability of the process. A further advantage of ncSi:H is its ability to harvest light across the near-infrared to visible wavelength range which provides opportunities for photothermal reduction of $\mathrm{CO}_{2}$ using both the heat and light from the sun. If the reducing $\mathrm{SiH}$ surface of $\mathrm{ncSi}: \mathrm{H}$ could be maintained under reaction conditions the reduction of $\mathrm{CO}_{2}$ could potentially be made catalytic.

\section{Results}

Synthesis and characterization of hydride-terminated ncSi. Hydride-terminated silicon nanocrystals, denoted ncSi:H, were obtained through a two-step synthesis reported before ${ }^{24}$. The source of ncSi:H is silicon monoxide $\mathrm{SiO}$, a low-cost commodity material available in kilogram quantities. Thermal treatment of $\mathrm{SiO}$ in a 5\% $\mathrm{H}_{2} / \mathrm{Ar}$ environment causes a redox disproportionation reaction in which the formally $\mathrm{Si}$ (II) in $\mathrm{SiO}$ is simultaneously reduced to $\mathrm{Si}(0)$ and oxidized to $\mathrm{Si}(\mathrm{IV})$. The so-formed $\mathrm{Si}(0)$ undergoes nucleation and growth to form ncSi in a $\mathrm{SiO}_{2}$ matrix $^{25}$. The size of the produced $\mathrm{ncSi}$ is within the range of 2-7 nm (ref. 24). Subsequent extraction of the ncSi from the $\mathrm{SiO}_{2}$ surrounding matrix is accomplished using aqueous $\mathrm{HF}$, and the product is a brown powder comprised of ncSi:H (Fig. 1a). Owing to their small sizes, a notably large surface area of $368 \mathrm{~m}^{2} \mathrm{~g}^{-1}$ was determined for $\mathrm{ncSi}: \mathrm{H}$ by nitrogen gas adsorption (Supplementary Fig. 1). Scanning electron microscopy (SEM) investigations of the $\mathrm{ncSi}: \mathrm{H}$ samples show they consist of aggregates of nanocrystals with textural nanoporosity (Fig. 1b), which is consistent with the large surface area measured. If we regard such textural interstices as pores, the mode pore size is $3.5 \mathrm{~nm}$ and the pore volume is $0.381 \mathrm{ccg}^{-1}$, determined from the nitrogen gas adsorption experiment (Supplementary Fig. 1). In Fig. 1c the powder X-ray diffraction pattern of a typical ncSi:H sample is depicted. All diffraction peaks can be assigned to silicon with no obvious ones, amorphous or crystalline, from $\mathrm{SiO}$ or $\mathrm{SiO}_{2}$ being detected. The surface of the obtained ncSi can be seen from Fourier transform infrared spectroscopy (FTIR) to contain plenty of $\mathrm{Si}: \mathrm{H}$ bonds, providing the necessary capacity for reducing $\mathrm{CO}_{2}$ into CO (Fig. 1d). The ultraviolet-vis diffuse reflectance spectra of the brown ncSi:H sample shows a strong broad-band optical absorption increasing in absorptivity as it traverses from the near infrared to ultraviolet wavelength range arising from a convolution of quantum size effects in the ncSi: $\mathrm{H}$ size distribution (Supplementary Fig. 2), rendering $\mathrm{ncSi}: \mathrm{H}$ a potentially effective photothermal $\mathrm{CO}_{2}$ reducing agent.

CO production from $\mathrm{CO}_{2}$ in the absence and presence of $\mathrm{H}_{2}$. The reactivity of these ncSi:H samples towards $\mathrm{CO}_{2}$ was first studied in a batch reactor irradiated with a metal halide lamp, in the absence and presence of $\mathrm{H}_{2}$ at $150{ }^{\circ} \mathrm{C}$, for multiple cycles (Fig. 2). To ensure the products of the reactions did not originate from adventitious carbon residues in the $\mathrm{ncSi}: \mathrm{H}$ samples, isotope labelled ${ }^{13} \mathrm{CO}_{2}$ was used to authenticate the origin of the reduction reaction. In the absence of $\mathrm{H}_{2}$, we observed a notable initial CO production rate as high as $4.5 \mu \mathrm{mol} \mathrm{h}^{-1} \mathrm{~g}^{-1}$ for an incident solar intensity of 1 sun at $150{ }^{\circ} \mathrm{C}$. The rate decreased in the following cycles but the sample was still active over $160 \mathrm{~h}$ (Fig. 2). It is important to note that ${ }^{13} \mathrm{CO}$ was found as the dominant product and no other ${ }^{13} \mathrm{C}$-containing compounds were detected (except for unreacted ${ }^{13} \mathrm{CO}_{2}$ ). The results of the batch experiments unequivocally demonstrate that $\mathrm{ncSi}: \mathrm{H}$ itself can heterogeneously reduce $\mathrm{CO}_{2}$ :

$$
\mathrm{CO}_{2}+\mathrm{ncSi}: \mathrm{H} \rightarrow \mathrm{CO}+\mathrm{ncSi}(\mathrm{O}): \mathrm{H},
$$

where $\mathrm{ncSi}(\mathrm{O}): \mathrm{H}$ stands for surface oxidized $\mathrm{ncSi}: \mathrm{H}$.

With both $\mathrm{H}_{2}$ and $\mathrm{CO}_{2}$ in the reactor, the initial $\mathrm{CO}$ production rate is about half of that for the case with the presence of only $\mathrm{CO}_{2}$, as expected because the partial pressure of $\mathrm{CO}_{2}$ is cut by half. This further confirms that $\mathrm{CO}_{2}$ was indeed a reactant. Notably, the rate of subsequent runs decreases much more slowly (Fig. 2), showing different kinetics, which suggests $\mathrm{H}_{2}$ likely gets involved in the $\mathrm{CO}_{2}$ reduction process. Unlike the case of only $\mathrm{CO}_{2}$ present in the reactor, where the $\mathrm{CO}$ production rate dropped significantly even at the second run, we instead observed an increased CO production rate when we introduced $\mathrm{H}_{2}$ to the reactor (Supplementary Fig. 3). Although the following tests showed the rate was still gradually decreasing, the presence of $\mathrm{H}_{2}$ seemed to aid in retaining more active sites, for example inhibiting the reaction between $\mathrm{Si}-\mathrm{H}$ and adsorbed/product $\mathrm{H}_{2} \mathrm{O}$ to yield $\mathrm{H}_{2}$ (ref. 14).

$$
\mathrm{Si}-\mathrm{H}+\mathrm{H}_{2} \mathrm{O} \rightarrow \mathrm{Si}-\mathrm{OH}+\mathrm{H}_{2},
$$

according to the simple Le Chatelier's principle, and similarly inhibiting the hydride loss to released $\mathrm{H}_{2}$ on heating ${ }^{26}$ :

$$
\mathrm{Si}-\mathrm{H}+\mathrm{H}-\mathrm{Si} \rightarrow \mathrm{Si}-\mathrm{Si}+\mathrm{H}_{2} \text {. }
$$

As discussed later, the FTIR spectrum of ncSi:H after reaction with both $\mathrm{H}_{2}$ and $\mathrm{CO}_{2}$ also exhibits less surface $\mathrm{Si}-\mathrm{O}-\mathrm{Si}$ but more 

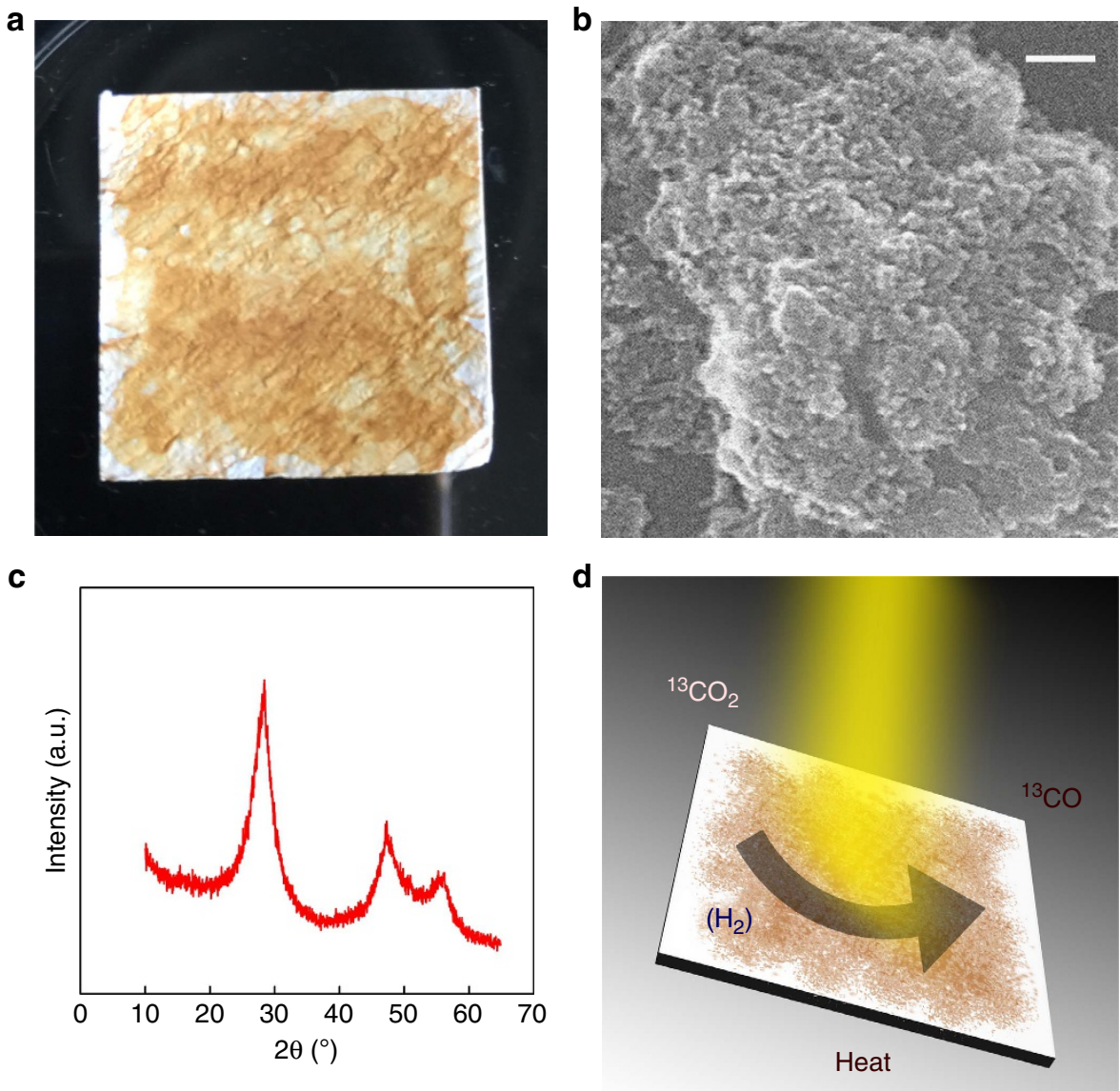

Figure 1 | Characterization of hydride-terminated ncSi. (a) As-synthesized powder comprised of ncSi:H deposited on a borosilicate glass fibre filter support. (b) SEM image of a film sample made of dried ncSi:H from a pentane dispersion. Scale bar, $100 \mathrm{~nm}$. (c) Powder X-ray diffraction pattern of ncSi:H, diffraction the main reflections peaks for nanocrystalline $\mathrm{Si}$. (d) Schematic illustration of the reduction of $\mathrm{CO}_{2}$ to $\mathrm{CO}_{\text {by }} \mathrm{ncSi}: \mathrm{H}$.

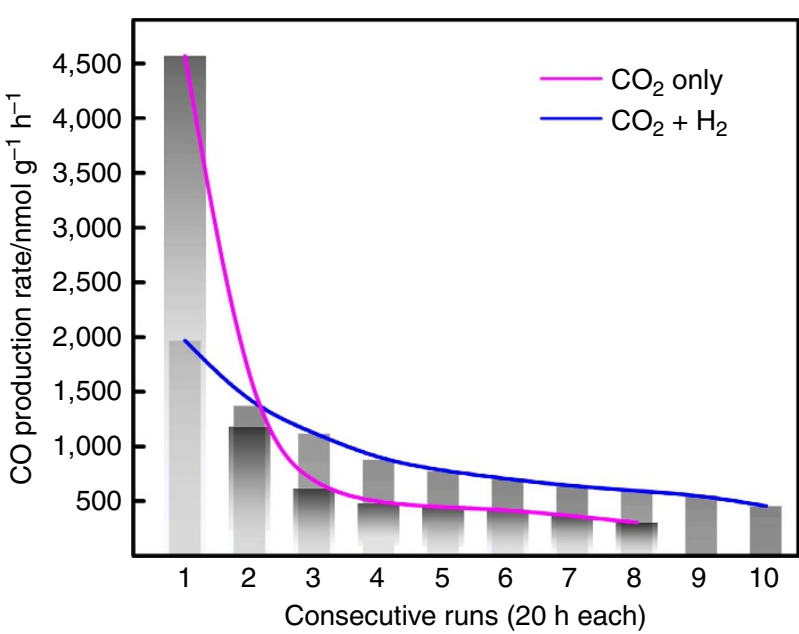

Figure 2 | Light-driven $\mathrm{CO}_{\mathbf{2}}$ reduction. $\mathrm{CO}$ production rates (pure ${ }^{13} \mathrm{CO}_{2}$ in the batch reactor at $150^{\circ} \mathrm{C}$ ) for eight cycles, and $\mathrm{CO}$ production rates $\left({ }^{13} \mathrm{CO}_{2}\right.$ and $\mathrm{H}_{2}$ with 1:1 ratio in the batch reactor at $\left.150^{\circ} \mathrm{C}\right)$ for 10 cycles, both under light (one sun) with the same total pressure of 27 p.s.i.

$\mathrm{Si}-\mathrm{OH}$, compared with that of ncSi:H reacted with only $\mathrm{CO}_{2}$ (Fig. 3). Importantly, the ultraviolet-vis diffuse reflectance spectrum is less blue-shifted, again indicating lesser amounts of surface oxidation (Supplementary Fig. 2).

To further understand the reaction mechanism, all ncSi:H samples were studied by FTIR spectroscopy before and after

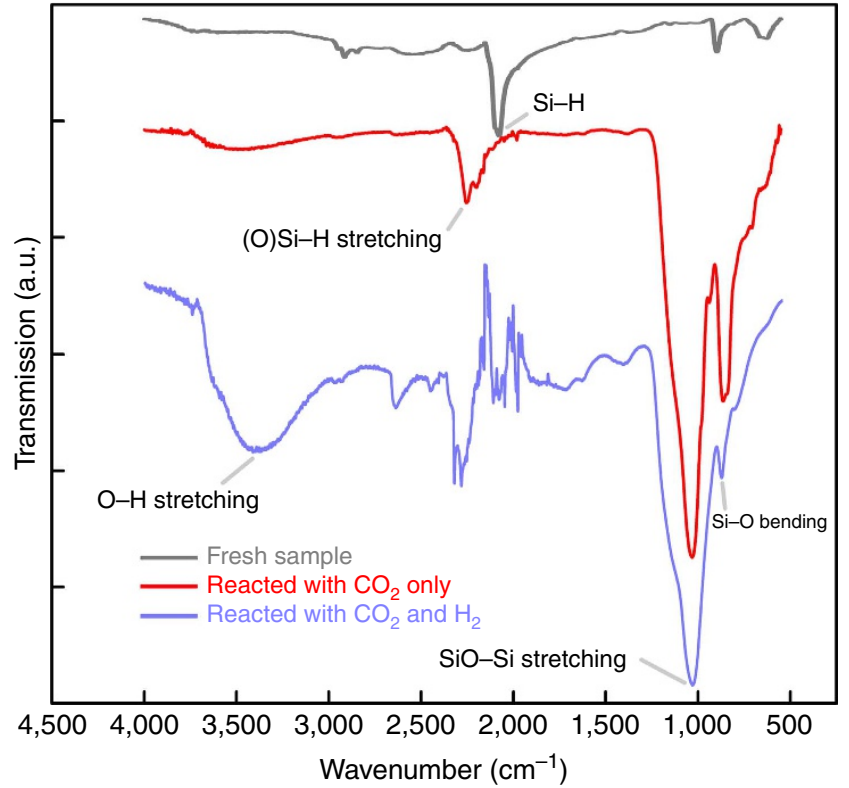

Figure 3 | FTIR study of surface properties. FTIR spectra of fresh ncSi:H powder before the reaction, after the reaction with ${ }^{13} \mathrm{CO}_{2}$ only for over $160 \mathrm{~h}$, and after the reaction with both ${ }^{13} \mathrm{CO}_{2}$ and $\mathrm{H}_{2}$ for over $200 \mathrm{~h}$.

testing, to gain an insight into the surface chemistry responsible for the products formed from the reaction of $\mathrm{CO}_{2}$ and $\mathrm{CO}_{2} / \mathrm{H}_{2}$ with ncSi:H, respectively. FTIR studies of the ncSi:H samples 
subjected to the testing conditions described above, before and after exposure to $\mathrm{CO}_{2}$ or $\mathrm{CO}_{2} / \mathrm{H}_{2}$ reactants for many cycles are shown in Fig. 3. The FTIR spectra indicate that before the reaction, the characteristic $\mathrm{Si}-\mathrm{H}$ stretching mode is dominant on the ncSi:H surface, with a little amount of residual $\mathrm{CH}_{\mathrm{x}}$ species from pentane extraction observed at $\sim 2,900 \mathrm{~cm}^{-1}$. After reaction with only $\mathrm{CO}_{2}$ for a significant number of cycles, accompanied by the aforementioned decrease of the $\mathrm{CO}$ production rate, the surface of $\mathrm{ncSi}: \mathrm{H}$ was oxidized and $\mathrm{Si}-\mathrm{O}-\mathrm{Si}$ and $\mathrm{Si}-\mathrm{OH}$ species were formed, which resembles the situation for oxidized Si nanowire surfaces ${ }^{27}$. Interestingly, there was still considerable amounts of $\mathrm{OSi}-\mathrm{H}$ species remaining on the surface seen at around $2,250 \mathrm{~cm}^{-1}$. Compared with the original $\mathrm{SiSi}-\mathrm{H}$, the hydride peak shifted from around $2,100 \mathrm{~cm}^{-1}$ to larger wavenumbers, which is diagnostic of some surface oxidation $^{28}$. These results suggest that only the non-oxidized related surface $\mathrm{Si}-\mathrm{H}$ sites are responsible for the reduction of $\mathrm{CO}_{2}$ to $\mathrm{CO}$, and the reaction is most likely stoichiometric through $\mathrm{O}$ transfer from $\mathrm{CO}_{2}$ to the surface of ncSi:H. This is supported by the result of a control test, in which a ncSi:H film was oxidized in air and daylight conditions for weeks, and showed no detectable production of $\mathrm{CO}$. In contrast, in the presence of $\mathrm{H}_{2}$, a higher proportion of surface $\mathrm{Si}-\mathrm{OH}$ groups are formed after reacting for a similar amount of time, which again implies $\mathrm{H}_{2}$ may play a role in the $\mathrm{CO}_{2}$ reduction process. Nevertheless, with our test condition the presence of $\mathrm{H}_{2}$ could not reinstate the non-oxidized $\mathrm{Si}-\mathrm{H}$ surface, thus the reaction was still considered not catalytic. Note that the residual organics are being removed during reaction (Fig. 3) and are not the source of reducing ${ }^{13} \mathrm{CO}_{2}$ to ${ }^{13} \mathrm{CO}$. This is further confirmed by a control test where we intentionally grafted a decyl group onto ncSi via hydrosilylation. The ${ }^{13} \mathrm{CO}$ did not increase but rather dropped significantly proving that the $\mathrm{Si}-\mathrm{H}$ is the active site.

The surface oxidation was further confirmed by probing the dangling bonds on $\mathrm{ncSi}: \mathrm{H}$ by electron paramagnetic resonance (EPR). We observed split peaks for the sample sealed in $\mathrm{CO}_{2}$ when the temperature was increased to $170^{\circ} \mathrm{C}$ both in dark and light (Fig. 4b). The small peaks at 3,351 G and at 3,332 $\mathrm{G}$ were hardly seen for the control sample under $\mathrm{N}_{2}$ (Fig. 4a). While the main signals (in all six spectra) are attributed to silicon dangling bonds in a disordered environment (with $\mathrm{g} \sim 2.0081$ ) $^{28,29}$, the new feature that emerged in the presence of $\mathrm{CO}_{2}$ should originate from the generation of the interface between the ncSi core and the surface oxidation shell. This new feature is similar to the well-known $\mathrm{P}_{b}$ centre in bulk $\mathrm{Si} / \mathrm{SiO}_{2}$ interfaces ${ }^{28,30,31}$, with an observed $g$ value $g_{\|}=2.0027$.

Effects of light and temperature. Our standard test condition includes irradiation with light, but the same reaction to reduce $\mathrm{CO}_{2}$ to $\mathrm{CO}$ can also be enabled thermally. In the absence of illumination, detectable amounts of $\mathrm{CO}$ can be observed after reaction over $20 \mathrm{~h}$ at around $130^{\circ} \mathrm{C}$. The production rate quickly increased to $1 \mu \mathrm{molh}^{-1} \mathrm{~g}^{-1}$ at $150^{\circ} \mathrm{C}$ and further exceeded $5 \mu \mathrm{molh}^{-1} \mathrm{~g}^{-1}$ at $170^{\circ} \mathrm{C}$ (Fig. 5). In most cases, the samples show higher $\mathrm{CO}$ production rates in the light at the same heating temperature except in the case of $170^{\circ} \mathrm{C}$ when the sample shows slightly higher CO production rate in the dark. The reason is that the studies on the temperature and light effects shown in Fig. 5 were conducted using the same sample for each temperature, following the sequence of first in dark then in light, being consistent throughout the whole experiment. Therefore there might be less reactive sites for the light test after the dark test was done, showing the same decreasing trend for the consecutive runs shown in Fig. 2. Instead, when a fresh ncSi:H sample was directly tested at $170^{\circ} \mathrm{C}$ in light, the $\mathrm{CO}$ production rate for the first run reaches up to $17 \mu \mathrm{molh}^{-1} \mathrm{~g}^{-1}$, roughly three times of that in the dark at the same temperature.

We do not observe new products other than ${ }^{13} \mathrm{CO}$ and the EPR results show very similar patterns regardless of the irradiation with light (Fig. 4). Most importantly with only light irradiation at the intensity of one sun but without heating we did not obtain observable amounts of ${ }^{13} \mathrm{CO}$. Thus we attribute the enhanced conversion rate to the photothermal effect of ncSi:H. In other words, the local temperature at the $\mathrm{ncSi}: \mathrm{H}$ surface was higher with light irradiation than in the dark under similar thermal heating conditions, which is responsible for the observed light enhancement effect. Significant photothermal effects of $\mathrm{Si}$ nanostructure have been well documented in recent years. For example, the $\mathrm{CO}_{2}$ reduction rate of ruthenium nanoparticles was found to be greatly enhanced by the photothermal effect of black $\mathrm{Si}$ nanowires ${ }^{32}$. Porous Si nanoparticles have been used for photothermal therapy ${ }^{33}$. For Si nanocrystals, laser light could induce intense local heating ${ }^{34}$, and the photothermal effect of $\mathrm{ncSi}$ increases with irradiation energy, consistent with a combination of thermalization of hot carriers under irradiation greater in energy than the bandgap (ultraviolet/visible light) and defect-mediated heating processes (induced by both ultraviolet/ visible light and infrared light $)^{35}$. A preliminary Raman study also shows that laser light could significantly heat up Si nanocrystals embedded in $\mathrm{SiO}_{\mathrm{x}}$ matrix (Supplementary Fig. 4). As shown in Fig. 5, the enhancement effect is more pronounced at $130{ }^{\circ} \mathrm{C}$ owing to the largest local temperature difference at the ncSi:H surface between dark and light conditions. Intuitively, the conversion rate could be further improved with more incident photons reaching the $\mathrm{ncSi}: \mathrm{H}$ surface. To further confirm the light enhancement mechanism, we also performed the reaction in $\mathrm{CO}_{2}$ and $\mathrm{H}_{2}$ at $150^{\circ} \mathrm{C}$ but with the irradiation of significantly higher intensity light from a Xe lamp ( $\sim 15$ suns). Amazingly, a 100 times boost of the rate to $\sim 250 \mu \mathrm{molh}^{-1} \mathrm{~g}^{-1}$ was observed, which is comparable to the best reported $\mathrm{CO}_{2}$ reduction catalysts (Fig. 6). It is notable that it is convenient to achieve 15 suns of light under daily sunlight with the use of a commercial solar concentrator. When illuminated with more concentrated light with the intensity of 20 suns, significant amounts of $\mathrm{CO}$ can be produced without providing external heating (Supplementary Fig. 5), but the ${ }^{13} \mathrm{CO}$ rate was still decreasing over consecutive runs even in the presence of $\mathrm{H}_{2}$ (Supplementary Table 1), consistent with the decreasing trend observed under the other reaction conditions (Supplementary Tables 1-3). While the exact role of $\mathrm{H}_{2}$ in the reduction process needs further study, it is believed that the presence of $\mathrm{H}_{2}$ used in these experiments is beneficial for maintaining the reductive atmosphere that minimizes the undesired surface oxidation and dehydrogenation of $\mathrm{ncSi}: \mathrm{H}^{36}$

Stability of hydride-terminated ncSi in air. As discussed above, the reductive surface of $\mathrm{ncSi}: \mathrm{H}$ is crucial for converting $\mathrm{CO}_{2}$ into CO. A common concern would be the stability of ncSi:H against oxidation during storage. One may expect that only freshly prepared samples are active and must be handled under humidity and oxygen free conditions, which may not be convenient for scale-up for industrial applications. Contrary to common belief, our ncSi:H powder is surprisingly stable if stored in air with proper care. For example, throughout an 11-day storage in a dark cabinet, the $\mathrm{CO}$ production rate was still as high as the rate shown by the fresh sample (Fig. 7). Even after an incredibly long time of two months, the rate only dropped a little to $1.62 \mu \mathrm{mol} \mathrm{h}-1 \mathrm{~g}^{-1}$. Our FTIR results also implied very little oxidation with much of the $\mathrm{Si}-\mathrm{H}$ preserved under such conditions (Supplementary Fig. 6). However, these nanocrystals quickly lost their reducing 
a

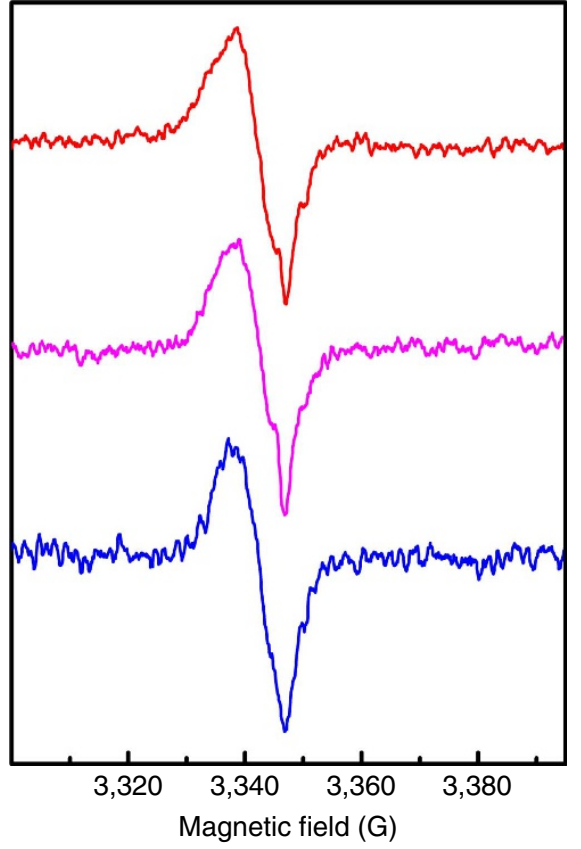

b

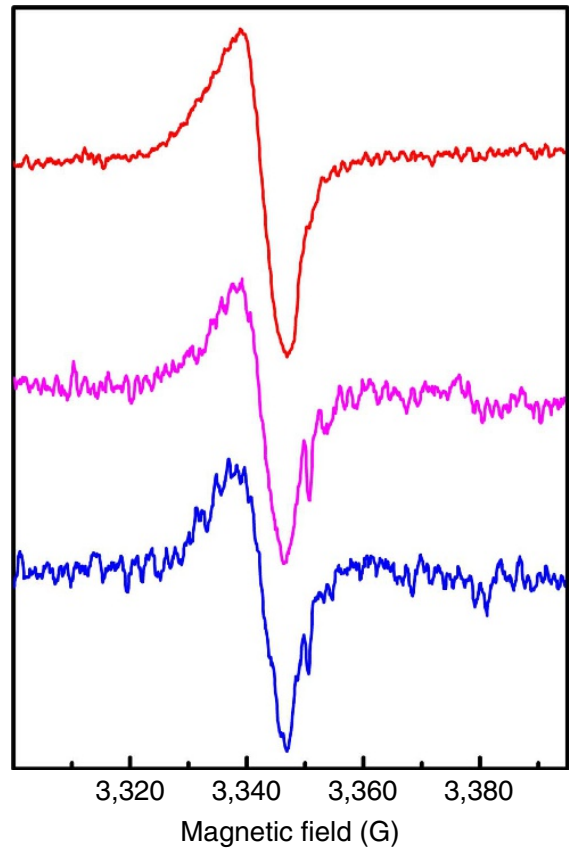

Figure 4 | EPR studies. EPR spectra of ncSi:H samples (a) in $\mathrm{N}_{2}$ (red, at room temperature; pink, at $170^{\circ} \mathrm{C}$ in dark; blue, at $170{ }^{\circ} \mathrm{C}$ with 0.5 sun); microwave frequency, $9.393 \mathrm{GHz}$, (b) in $\mathrm{CO}_{2}$ (red, at room temperature; pink, at $170^{\circ} \mathrm{C}$ in dark for over half an hour; blue, at $170{ }^{\circ} \mathrm{C}$ with 0.5 sun for another half an hour); microwave frequency, $9.393 \mathrm{GHz}$.

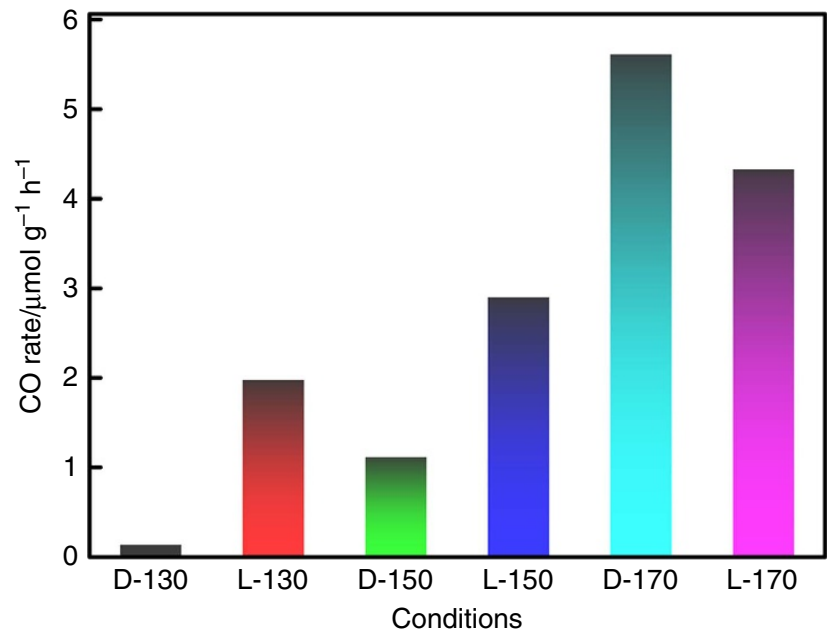

Figure 5 | Temperature effect. $\mathrm{CO}$ production rates of three ncSi:H film samples tested at different heating temperatures $\left(130^{\circ} \mathrm{C}, 150^{\circ} \mathrm{C}\right.$, and $170^{\circ} \mathrm{C}$ ), first in the dark (D) and then in the light $(\mathrm{L})$.

power stored under similar conditions but exposed to ambient room light. Apparently, the oxidation of the ncSi:H surface can be greatly accelerated even with ambient light ${ }^{37}$. Therefore, the key to maintain the reductive surface of $\mathrm{ncSi}: \mathrm{H}$ during the storage in air is away from light.

DFT simulations. While this paper reports an important first step in a brand new approach to $\mathrm{CO}_{2}$ reduction with still much to explore, we have conducted preliminary density functional theory (DFT) calculations to probe the identity, structural and chemical reactivity of the surface species involved in the reaction in more detail. We choose $\sim 1 \mathrm{~nm} \mathrm{Si}_{35} \mathrm{H}_{36}$ model for this study. Our thermogravimetric analysis (TGA) confirms the $\mathrm{H}$ amount is comparable to the estimated amount from such models

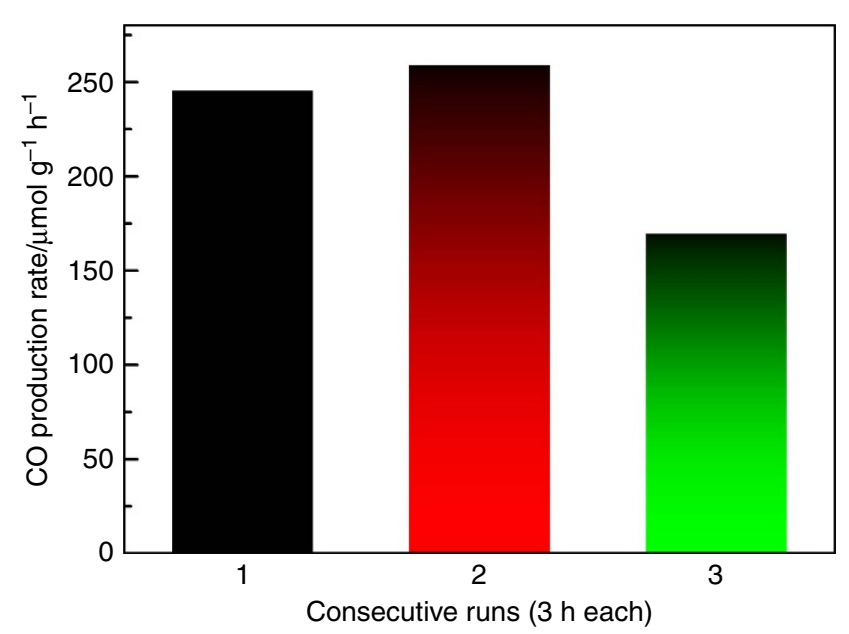

Figure 6 | Light source effect. Enhanced $\mathrm{CO}$ production rates of a ncSi:H sample illuminated with $\sim 15$ suns.

(Supplementary Fig. 7). The details of the computational method and models are given in the methods section. It is known that surface adsorption can lower the $\mathrm{CO}_{2}$ reduction potential in aqueous systems, making the reaction possible on semiconductors with a conduction band potential lower than the single-electron reduction potential of $\mathrm{CO}_{2}$ (refs 38,39). It is conceivable that $\mathrm{CO}_{2}$ adsorption could similarly facilitate its reduction in gas phase reactions. Thus to explore the interaction between the gaseous $\mathrm{CO}_{2}$ molecule with the ncSi:H sample we also investigated computationally the $\mathrm{CO}_{2}$ adsorption on all possible surface sites. We placed the $\mathrm{CO}_{2}$ molecule in the vicinity of $\mathrm{SiH}_{2}$ ( $\mathrm{Si}$ bonded with $2 \mathrm{H}$ 's, Fig. $8 \mathrm{a}$ ), $\mathrm{SiH}$ ( $\mathrm{Si}$ bonded with $1 \mathrm{H}$, Fig. $8 \mathrm{c}$ ), and $\mathrm{Si}(\mathrm{Si}$ with dangling bond Fig. 8e), surface sites and optimized each system. This analysis showed that the $\mathrm{CO}_{2}$ molecule will not interact with surface $\mathrm{SiH}_{2}$ and will remain intact (Fig. 8b). However, it will interact with the other two sites. At the dangling 


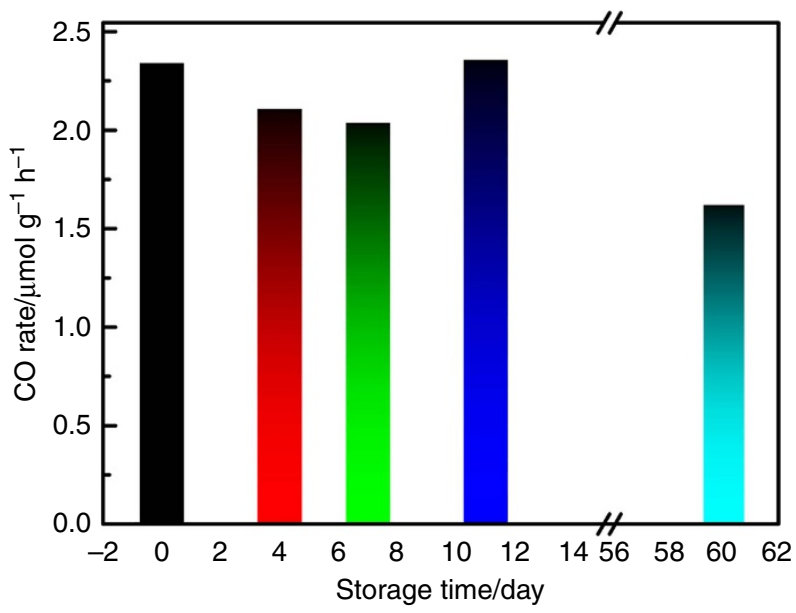

Figure 7 | Stability of hydride-terminated ncSi during storage. CO production rate of ncSi:H film samples after different time spans of storage, which demonstrates the stability of the ncSi:H sample in air without the exposure to light.

bond $\mathrm{Si}$ site $\mathrm{CO}_{2}$ molecularly adsorbs and bends as shown in Fig. 8f. The calculated binding energy of $\mathrm{CO}_{2}$ on the $\mathrm{Si}$ site is $0.63 \mathrm{eV}$. The $\mathrm{C}-\mathrm{O}$ bond lengths for $\mathrm{CO}_{2}$ molecule increased from 1.16 to $1.22 \AA$ and $1.53 \AA$, and the bond angle reduced from $180^{\circ}$ to $121.2^{\circ}$. However the dangling bond $\mathrm{Si}$ site is not able to dissociate $\mathrm{CO}_{2}$. Interestingly, the $\mathrm{SiH}$ site managed to dissociate $\mathrm{CO}_{2}$ into $\mathrm{CO}$ and $\mathrm{Si}-\mathrm{OH}$ endothermically (adsorption energy $\approx 0.11 \mathrm{eV}$ ) making surface $\mathrm{SiH}$ the most favourable site for $\mathrm{CO}_{2}$ reduction reaction in $\mathrm{ncSi}: \mathrm{H}$ system (Fig. 8d). The $\mathrm{C}-\mathrm{O}$ and $\mathrm{O}-\mathrm{H}$ bond lengths of the products are 1.17 and $1.01 \AA$, respectively, the Bader charges on $\mathrm{O}$ and $\mathrm{C}$ of $\mathrm{CO}$ are $-1.79 \mathrm{e}$ and $+1.74 \mathrm{e}$, respectively, and Bader charge on $\mathrm{O}$ and $\mathrm{H}$ of $\mathrm{OH}$ are $-2.07 \mathrm{e}$ and $0.00 \mathrm{e}$, respectively. The strong bonds and charge distribution show that products formed by $\mathrm{CO}_{2}$ dissociation on the $\mathrm{SiH}$ site are very stable.

To examine if $\mathrm{H}_{2}$ can reinstate surface $\mathrm{Si}-\mathrm{H}$ sites, the interaction of $\mathrm{H}_{2}$ with $\mathrm{Si}-\mathrm{OH}$ formed after $\mathrm{CO}_{2}$ dissociation was also investigated. We simulated three different configurations. In the first configuration $\mathrm{H}_{2}$ was placed horizontally about $1.17 \AA$ away from surface SiOH (Supplementary Fig. 10a), in the second configuration $\mathrm{H}_{2}$ was placed horizontally about $0.67 \AA$ away from surface $\mathrm{SiOH}$ (Supplementary Fig. 10b) and the in third configuration $\mathrm{H}_{2}$ was placed vertically about $0.63 \AA$ away from surface $\mathrm{SiOH}$ (Supplementary Fig. 10c). While optimizing all three configurations, $\mathrm{H}_{2}$ showed no interaction with the surface $\mathrm{OH}$ and remained intact moving away from the $\mathrm{ncSi}: \mathrm{H}$ surface. This shows that surface hydroxides are very stable as also indicated by bond length and charge distribution discussed above and that $\mathrm{H}_{2}$ cannot easily recover the $\mathrm{Si}-\mathrm{H}$. This result is consistent with the literature ${ }^{40}$ and experimentally observed decrease in rate over time.

\section{Discussion}

Unlike the reduction of $\mathrm{CO}_{2}$ by the molecular silanes, which goes through an intermediate species like $\mathrm{SiOCH}_{2} \mathrm{OSi}$ or $\mathrm{SiOCHO}^{41}$, in the case of $\mathrm{ncSi}: \mathrm{H}$ we propose that the product $\mathrm{CO}$ directly leaves the surface of ncSi:H after $\mathrm{O}$ abstraction from $\mathrm{CO}_{2}$ without the $\mathrm{C}$ bonding to $\mathrm{H}$. If our $\mathrm{ncSi}: \mathrm{H}$ system went the same route as molecular silanes, we might expect to see $\mathrm{CH}_{\mathrm{x}}$ surface species and ultimately $\mathrm{CH}_{4}$ and/or $\mathrm{CH}_{3} \mathrm{OH}$ as the products.

However we see no ${ }^{13} \mathrm{C}$ labelled species on the Si surface in the IR spectrum, and no ${ }^{13} \mathrm{C}$ labelled organic products other than CO. These diagnostics suggest that the reaction might not go

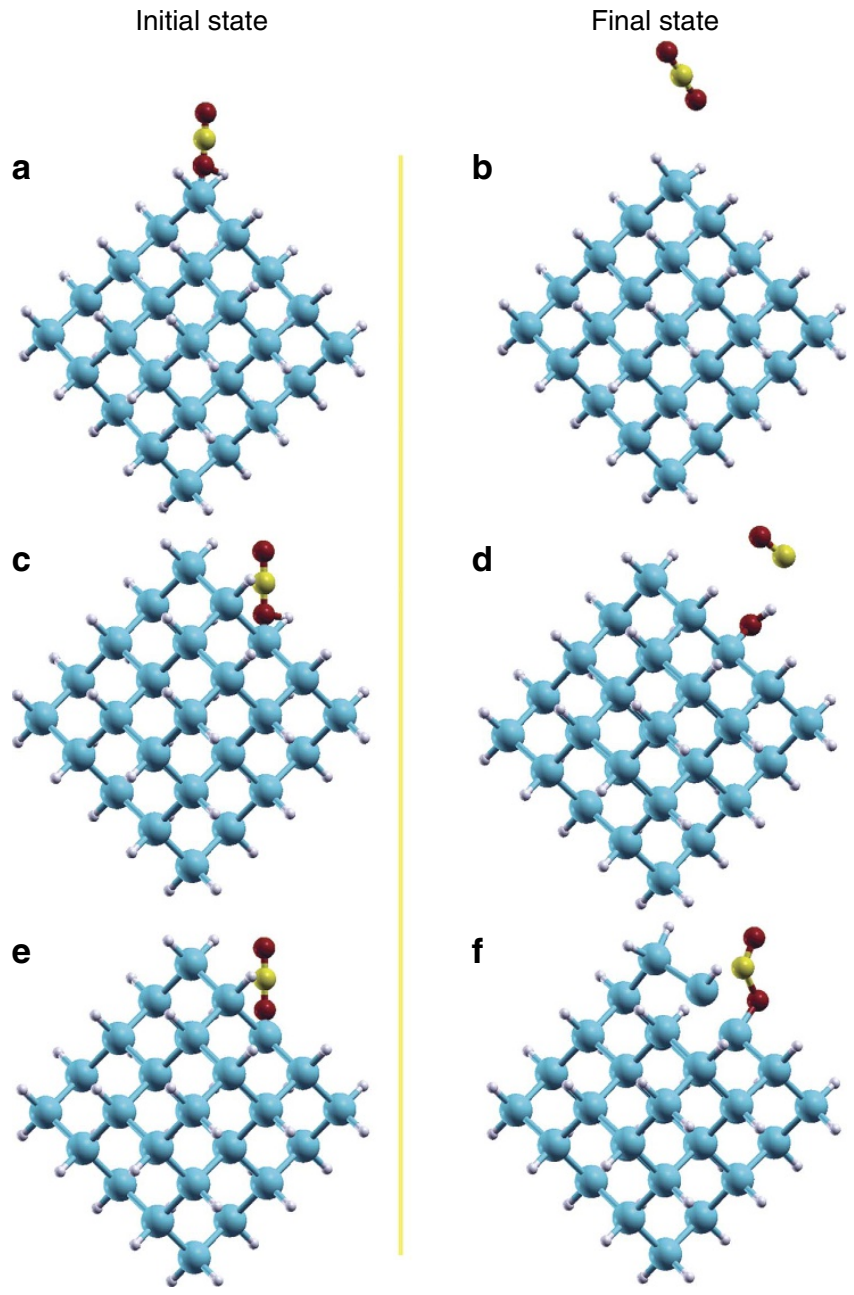

Figure 8 | The DFT models. The initial models of $\mathrm{CO}_{2}$ adsorption on (a) $\mathrm{SiH}_{2}$, (c) $\mathrm{SiH}$ and (e) Si surface sites. The final optimized models of $\mathrm{CO}_{2}$ adsorption on (b) $\mathrm{SiH}_{2}$, (d) $\mathrm{SiH}$ and (f) Si surface sites.

through the insertion of $\mathrm{CO}_{2}$ into the $\mathrm{Si}-\mathrm{H}$ bonds as found with molecular silanes with added catalysts. Instead, the insertion of $\mathrm{O}$ into the Si surface directs this heterogeneous reduction reaction to produce only $\mathrm{CO}$. The $\mathrm{Si}-\mathrm{H}$ surface of ncSi:H likely facilities the adsorption/binding of $\mathrm{CO}_{2}$ (ref. 42), and the large surface curvature and large surface to volume ratio likely facilitates the surface reactivity ${ }^{43}$, features which differentiate ncSi from bulk Si and molecular silanes. It is also important to note that the gas phase reaction temperature is quite different from that used with molecular silanes. Since the reaction also occurred in the dark, it is likely that the reduction reaction was able to be thermally driven without the need of exciton generation by light. Therefore, we attribute this unique gas-phase heterogeneous reduction reaction of $\mathrm{CO}_{2}$ by $\mathrm{ncSi}: \mathrm{H}$ to its very small size, high surface area and highly reactive $\mathrm{SiH}$ surface. The impurity of $\mathrm{F}$ after $\mathrm{HF}$ etching during synthesis was negligible and should play a trivial role for very small Si nanocrystals with high surface curvature ${ }^{44}$, with only 1.43 at\% F compared with 98.57 at\% Si determined by XPS after heating at $60^{\circ} \mathrm{C}$ in vacuum (spectra shown in Supplementary Fig. 11). With such vacuum thermal treatment, the sample was still active for $\mathrm{CO}_{2}$ reduction (Supplementary Fig. 5).

In the presence of $\mathrm{H}_{2}$, the production rate of $\mathrm{CO}$ from $\mathrm{CO}_{2}$ was enhanced. Apparently, the presence of $\mathrm{H}_{2}$ is beneficial for maintaining the $\mathrm{SiH}$ surface of $\mathrm{ncSi}: \mathrm{H}$ in an un-oxidized state. 
Minimizing adventitious air oxidation especially in the light seems to be another way to preserve activity. Pertinently, light can be helpful in the reduction of $\mathrm{CO}_{2}$ via the oxidation of $\mathrm{ncSi}: \mathrm{H}$ by the abstracted $\mathrm{O}$ from the $\mathrm{CO}_{2}$ itself. The potential of concentrated light to further enhance the $\mathrm{CO}_{2}$ reduction rate is also apparent. By optimizing the photothermal effect in ncSi:H it may prove possible to boost $\mathrm{CO}_{2}$ reduction rates to technologically significant values. If reduced to practice this would make earth abundant low cost silicon an attractive material as part of a global $\mathrm{CO}_{2}$ utilization strategy to meet IPCC emission targets by 2035 .

Almost four decades have passed since the first report that sunlight can power the reduction of $\mathrm{CO}_{2}$ to carbon containing products in aqueous suspensions using semiconductor powder photocatalysts ${ }^{45}$. Since that time the photoreduction of $\mathrm{CO}_{2}$ by $\mathrm{H}_{2} \mathrm{O}$ or $\mathrm{H}_{2}$ have been studied in the aqueous and gas phase using almost every conceivable nanostructured composition imaginable ${ }^{32,46-49}$. While $\mathrm{CO}_{2}$ conversion rates and efficiencies of reported photocatalysts are still orders of magnitude below those required to inspire technological development ${ }^{50,51}$, progress towards achieving this objective has been steady and promising. One stumbling block along the road to success could prove to be the cost of scaling the photocatalyst to proportions of industrial relevance, because the compositions of the best photocatalysts are invariably comprised of rare and expensive elements. Overcoming this hurdle emphasizes the distinctiveness and significance of the work reported herein. It is indeed a surprising yet welcome discovery that plentiful, inexpensive and benign elemental silicon, synthesized in the form of ncSi:H made easily and cheaply from commercially available SiO, can exploit the reducing power of surface hydride to chemically reduce $\mathrm{CO}_{2}$ to $\mathrm{CO}-\mathrm{a}$ synthon for making methanol or hydrocarbons by well-established methods-at scientifically impressive $\sim \mathrm{mmolh}^{-1} \mathrm{~g}_{\text {cat }}^{-1}$ conversion rates. This advance bodes well for continued improvement by composition variations and doping methods, as well as size, shape and surface variations of ncSi: $\mathrm{H}$, to achieve a higher rate and perhaps even transform the seemingly stoichiometric reaction to catalytic. The ultimate goal is to achieve technologically relevant $\mathrm{CO}_{2}$ utilization rates of $\mathrm{molh}^{-1} \mathrm{~g}_{\text {cat }}^{-1}$, which translates into Gt $\mathrm{y}^{-1} \mathrm{t}_{\mathrm{cat}}^{-1}$.

Current global annual $\mathrm{CO}_{2}$ emissions from the use of fossil fuels amount to about 36 billion ton equivalents and are projected to reach 43 billion ton equivalents by 2030 . In the war against climate change, the consensus is that carbon dioxide capture and storage alone cannot solve this problem and to have a meaningful effect needs to be combined with chemical and catalytic processes that convert the carbon dioxide into value-added chemicals and fuels ${ }^{51}$. It might well take something as simple and elegant as $\mathrm{CO}_{2}$ fixation by ncSi:H to solve such a monumental global problem.

\footnotetext{
Methods

Synthesis of ncSi in silicon oxide matrix. Solid $\mathrm{SiO}$ (purchased from Sigma-Aldrich, - 325 mesh powder) was placed in a quartz reaction boat and transferred to a tube furnace. The samples were typically heated at a rate of $18^{\circ} \mathrm{C} \mathrm{min}^{-1}$ under a flow of $95 \% \mathrm{Ar} / 5 \% \mathrm{H}_{2}$ to a peak processing temperature of $900^{\circ} \mathrm{C}$, then held at that temperature for $1 \mathrm{~h}$ before the furnace was allowed to cool to room temperature.

Liberation of ncSi:H from silicon oxide matrix. For a typical batch synthesis, $0.3 \mathrm{~g}$ of $900{ }^{\circ} \mathrm{C}$ treated $\mathrm{SiO}$ powder was transferred to a Teflon beaker containing a mixture of $10 \mathrm{ml}$ of $95 \%$ ethanol (aq. Sigma Aldrich) and $20 \mathrm{ml}$ of $48 \% \mathrm{HF}$ (aq. Sigma Aldrich). Personnel should be well trained in the handling of HF. The mixture was stirred for $2 \mathrm{~h} 50 \mathrm{~min}$ to fully etch away the silicon oxide matrix. The hydride-terminated ncSi were then extracted from the aqueous solution into pentane. The scale of the batch could be enlarged as long as the volume of the beakers and flasks are sufficient for safe handling of chemicals, for example, starting with $2 \mathrm{~g}$ of $\mathrm{SiO}$ powder instead of $0.3 \mathrm{~g}$.
}

Characterization. Powder X-ray diffraction was performed on a Bruker D2-Phaser $\mathrm{X}$-ray diffractometer, using $\mathrm{Cu} \mathrm{K} \alpha$ radiation at $30 \mathrm{kV}$. The nitrogen sorption experiments were performed at $77 \mathrm{~K}$ on a Quantachrome Autosob-1-C instrument Prior to each adsorption measurement the samples were degassed at $60^{\circ} \mathrm{C}$ overnight under vacuum. The specific surface area was determined using the Brunauer-Emmett-Teller (BET) equation, applied to the best linear fit within the range of $0.05 \leq P / P_{0} \leq 0.35$. The cumulative pore volume and pore size distribution were determined using non-local density functional theory (NL-DFT). FTIR was performed using a Perkin Elmer Spectrum-One FT-IR fitted with a universal attenuated total reflectance (ATR) sampling accessory with a diamond coated zinc selenide window. For the oxidation study of the ncSi:H on the $\mathrm{KBr}$ pellet, the FTIR spectra were acquired using the transmission mode without the ATR accessory. Diffuse reflectance of the samples was measured using a Lambda 1050 ultraviolet/ VIS/NIR spectrometer from Perkin Elmer and an integrating sphere with a diameter of $150 \mathrm{~mm}$. The ncSi:H aggregates morphology was characterized by SEM using a QUANTA FEG 250 ESEM. EPR measurements were performed at room temperature and $170^{\circ} \mathrm{C}$ using a Bruker ECS-EMX X-band EPR spectrometer equipped with an ER4119HS cavity. An Oxford ITC503 temperature controller was utilized. Typical operating parameters were as follows: microwave frequency 9.363/9.393 GHz (for $\mathrm{N}_{2} / \mathrm{CO}_{2}$ ), microwave power $2.147 / 2.144 \mathrm{~mW}$ (for $\mathrm{N}_{2} / \mathrm{CO}_{2}$ ), modulation amplitude $1.000 \mathrm{G}$, sweep width $100 \mathrm{G}$ centred at $3347.25 \mathrm{G}$, time constant $0.01 \mathrm{~ms}$, total sweep time $300.00 \mathrm{~s}$, number of scans 4 . The EPR analysis was applied to dried ncSi:H samples, which were sealed in the $4 \mathrm{~mm}$ EPR tubes in the glove-box under a $\mathrm{N}_{2}$ gas atmosphere or sealed in $\mathrm{CO}_{2}$ gas. The TGA experiments were performed using a Discovery TGA (TA Instruments). The actual TGA test condition is described in Supplementary Fig. 7. X-ray photoelectron spectroscopy (XPS) was performed in an ultrahigh vacuum chamber with base pressure of $10^{-9}$ torr. The system used a Thermo Scientific K-Alpha XPS spectrometer, with an $\mathrm{Al} \mathrm{K} \mathrm{K}_{\alpha} \mathrm{X}$-ray source operating at $12 \mathrm{kV}, 6 \mathrm{~A}$ and X-ray wavelengths of $1486.7 \mathrm{eV}$. The spectra were obtained with analyser pass energy of $50 \mathrm{eV}$ with energy spacing of $0.1 \mathrm{eV}$. The sample for XPS analysis was prepared by drop casting ncSi: $\mathrm{H}$ in pentane on GaAs substrates and left in vacuum at $60^{\circ} \mathrm{C}$ for several hours. The data analysis was carried out using Thermo Scientific Avantage software.

Gas phase $\mathrm{CO}_{2}$ reduction measurements. Borosilicate glass microfiber filters were used as a substrate for gas phase reaction measurements to provide increased surface area as well as mechanical stability. A fresh dispersion of ncSi:H in pentane was dropped onto the filters and dried under $\mathrm{N}_{2}$ flow to yield films containing several $\mathrm{mg}$ of ncSi:H. Then the films were further dried under vacuum for at least $0.5 \mathrm{~h}$, before placing into the reactor. A total pressure of $\sim 27$ p.s.i. and a light intensity of one sun were the standard conditions for each run, otherwise the different conditions would be stated in the main text. The details of the reactor are listed as follows. These experiments were conducted in a custom fabricated $1.5-\mathrm{ml}$ stainless steel batch reactor with a fused silica view port sealed with Viton O-rings. The reactors were evacuated using an Alcatel dry pump prior to being purged with the reactant gases $\mathrm{H}_{2}(99.9995 \%)$ and $\mathrm{CO}_{2}(99.999 \%)$ at a flow rate of $6 \mathrm{ml} \mathrm{min}^{-}$ and a stoichiometry of 1:1 (stoichiometric for reverse water gas shift reaction). During purging, the reactors were sealed once they had been heated to the desired temperature. The reactor temperatures were controlled by an OMEGA CN616 6-Zone temperature controller combined with a thermocouple placed in contact with the sample. The pressure inside the reactor was monitored during the reaction using an Omega PX309 pressure transducer. Reactors were irradiated with a $1000 \mathrm{~W}$ Hortilux Blue metal halide bulb for a period of $\sim 22 \mathrm{~h}$. For the test irradiated with concentrated light, the reactor with a volume of $11.8 \mathrm{ml}$ was irradiated with a $300 \mathrm{~W}$ Xe lamp for a duration of $3 \mathrm{~h}$. Product gases were analysed with a flame ionization detector and thermal conductivity detector installed in a SRI-8610 gas chromatograph with a $3^{\prime}$ Mole Sieve 13a and $6^{\prime}$ Haysep D column. Isotope tracing experiments were performed using ${ }^{13} \mathrm{CO}_{2}$ (99.9 at\% Sigma Aldrich). The reactors were evacuated prior to being injected with $\mathrm{H}_{2}$ followed by ${ }^{13} \mathrm{CO}_{2}$. Isotope product gases were measured using an Agilent $7890 \mathrm{~A}$ gas chromatographic mass spectrometer (GC-MS) with a $60 \mathrm{~m}$ GS-CarbonPLOT column fed to the mass spectrometer.

DFT simulations. DFT calculations were carried out using Quantum ESPRESSO ${ }^{52}$ The plane-wave-pseudopotential approach, together with the Becke-LeeYang-Parr ${ }^{53,54}$ exchange-correlation functional, and norm-conserving pseudopotentials was utilized throughout the analysis. All calculations are spin polarized. The kinetic energy cut-offs of 40 and 400 Ry were used for the smooth part of the electronic wave functions and augmented electron density, respectively. The self-consistent field convergence criterion was set to $1 \times 10^{-6} \mathrm{Ry}$ per Bohr and the structures were relaxed using a Davidson type diagonalization method until the magnitude of the residual Hellmann-Feynman force on each surface atom was less than $10^{-3}$ Ry per Bohr. The Brillouin zone integrations at gamma point were performed for full geometry optimization. To model ncSi:H we choose a spherical region of about $1 \mathrm{~nm}$ from the center of bulk diamond cubic silicon lattice and saturated the dangling bonds on the surface with hydrogen. The terminated $\mathrm{Si}$ atoms are classified into $\mathrm{SiH}$ and $\mathrm{SiH}_{2}$ types leading to a $\mathrm{Si}_{35} \mathrm{H}_{36}$ structure as illustrated in Supplementary Fig. 8. Blue and white spheres in Supplementary Fig. 8 represent the $\mathrm{Si}$ and $\mathrm{H}$ atoms, respectively. The cluster was located in a 
$30 \times 30 \times 30 \AA$ cubic supercell. The relaxed structure is very similar to the previously reported structures ${ }^{55,56}$. To estimate the $\mathrm{Si}$ to $\mathrm{H}$ ratio in experimental samples that have mean size of about $3.5 \mathrm{~nm}$, we also modeled ncSi: $\mathrm{H}$ of size $3.5 \mathrm{~nm}$, as shown in Supplementary Fig. 9. The total number of atoms in this model is 1208 with $944 \mathrm{Si}$ and $264 \mathrm{H}$ atoms. However, since it is not feasible to work with such a large size model using DFT, we did not optimize this system and considered only the $\mathrm{Si}_{35} \mathrm{H}_{36}$ model for further DFT analysis.

Data availability. All relevant data are available on request from the authors.

\section{References}

1. Conibeer, G. et al. Silicon nanostructures for third generation photovoltaic solar cells. Thin Solid Films 511, 654-662 (2006).

2. Goodey, A. P., Eichfeld, S. M., Lew, K.-K., Redwing, J. M. \& Mallouk, T. E. Silicon nanowire array photoelectrochemical cells. J. Am. Chem. Soc. 129, 12344-12345 (2007)

3. Liu, C. Y., Holman, Z. C. \& Kortshagen, U. R. Hybrid solar cells from P3HT and Silicon Nanocrystals. Nano Lett. 9, 449-452 (2009).

4. Chan, C. K. et al. High-performance lithium battery anodes using silicon nanowires. Nat. Nanotechnol. 3, 31-35 (2008).

5. Hu, Y.-S. et al. Superior storage performance of a $\mathrm{Si} @ S i O_{\mathrm{x}} / \mathrm{C}$ nanocomposite as anode material for lithium-ion batteries. Angew. Chem. Int. Ed. 47, 1645-1649 (2008).

6. Cui, L.-F., Ruffo, R., Chan, C. K., Peng, H. \& Cui, Y. Crystalline-amorphous core-shell silicon nanowires for high capacity and high current battery electrodes. Nano Lett. 9, 491-495 (2009).

7. Zhou, Z. B., Xu, Y. H., Liu, W. G. \& Niu, L. B. High capacity Si/DC/MWCNTs nanocomposite anode materials for lithium ion batteries. J. Alloy. Compd. 493, 636-639 (2010).

8. Boukai, A. I. et al. Silicon nanowires as efficient thermoelectric materials. Nature 451, 168-171 (2008).

9. Hochbaum, A. I. et al. Enhanced thermoelectric performance of rough silicon nanowires. Nature 451, 163-167 (2008).

10. Shao, M. W., Cheng, L., Zhang, X. H., Ma, D. D. D. \& Lee, S. T. Excellent photocatalysis of HF-treated silicon nanowires. J. Am. Chem. Soc. 131, 17738-17739 (2009).

11. Ronge, J. et al. Monolithic cells for solar fuels. Chem. Soc. Rev. 43, 7963-7981 (2014).

12. Oh, I., Kye, J. \& Hwang, S. Enhanced photoelectrochemical hydrogen production from silicon nanowire array photocathode. Nano Lett. 12, 298-302 (2012).

13. Wang, F.-Y. et al. Highly active and enhanced photocatalytic silicon nanowire arrays. Nanoscale 3, 3269-3276 (2011).

14. Liu, D. et al. The nature of photocatalytic 'Water Splitting' on silicon nanowires. Angew. Chem. Int. Ed. 54, 2980-2985 (2015).

15. Xu, Z. G. et al. Photoluminescent silicon nanocrystal-based multifunctional carrier for pH-regulated drug delivery. ACS Appl. Mater. Inter. 4, 3424-3431 (2012).

16. Henstock, J. R., Canham, L. T. \& Anderson, S. I. Silicon: the evolution of its use in biomaterials. Acta Biomater. 11, 17-26 (2015).

17. Khandelwal, M. \& Wehmschulte, R. J. Deoxygenative reduction of carbon dioxide to methane, toluene, and diphenylmethane with $\left[\mathrm{Et}_{2} \mathrm{Al}\right]^{+}$as catalyst. Angew. Chem. Int. Ed. 51, 7323-7326 (2012).

18. Jansen, A., Görls, H. \& Pitter, S. Trans-[RuIICl $\left.(\mathrm{MeCN})_{5}\right]\left[\mathrm{RuIIICl}_{4}\left(\mathrm{MeCN}_{2}\right]\right.$ : a reactive intermediate in the homogeneous catalyzed hydrosilylation of carbon dioxide ${ }^{\dagger}$. Organometallics 19, 135-138 (2000).

19. Matsuo, T. \& Kawaguchi, H. From carbon dioxide to methane: homogeneous reduction of carbon dioxide with hydrosilanes catalyzed by zirconium - borane complexes. J. Am. Chem. Soc. 128, 12362-12363 (2006).

20. Riduan, S. N., Zhang, Y. \& Ying, J. Y. Conversion of carbon dioxide into methanol with silanes over N-heterocyclic carbene catalysts. Angew. Chem. Int. Ed. 48, 3322-3325 (2009).

21. Berkefeld, A., Piers, W. E. \& Parvez, M. Tandem frustrated Lewis pair/tris(pentafluorophenyl)borane-catalyzed deoxygenative hydrosilylation of carbon dioxide. J. Am. Chem. Soc. 132, 10660-10661 (2010).

22. Riduan, S. N., Ying, J. Y. \& Zhang, Y. Mechanistic insights into the reduction of carbon dioxide with silanes over N-heterocyclic carbene catalysts. Chem CatChem. 5, 1490-1496 (2013).

23. Kang, Z. H., Tsang, C. H. A., Wong, N. B., Zhang, Z. D. \& Lee, S. T. Silicon quantum dots: a general photocatalyst for reduction, decomposition, and selective oxidation reactions. J. Am. Chem. Soc. 129, 12090-12091 (2007).

24. Sun, W. et al. Switching-on quantum size effects in silicon nanocrystals. $A d v$. Mater. 27, 746-749 (2015).

25. Sun, W. et al. Silicon monoxide-a convenient precursor for large scale synthesis of near infrared emitting monodisperse silicon nanocrystals. Nanoscale $\mathbf{8}$, 3678-3684 (2016).
26. Neiner, D. \& Kauzlarich, S. M. Hydrogen-capped silicon nanoparticles as a potential hydrogen storage material: synthesis, characterization, and hydrogen release. Chem. Mater. 22, 487-493 (2010).

27. Peng, C. et al. Stability of hydrogen-terminated surfaces of silicon nanowires in aqueous solutions. J. Phys. Chem. C 115, 3866-3871 (2011).

28. Pereira, R. N., Rowe, D. J., Anthony, R. J. \& Kortshagen, U. Oxidation of freestanding silicon nanocrystals probed with electron spin resonance of interfacial dangling bonds. Phys. Rev. B 83, 155327 (2011).

29. Brodsky, M. H. \& Title, R. S. Electron spin resonance in amorphous silicon, germanium, and silicon carbide. Phys. Rev. Lett. 23, 581-585 (1969).

30. Poindexter, E. H., Caplan, P. J., Deal, B. E. \& Razouk, R. R. Interface states and electron spin resonance centers in thermally oxidized (111) and (100) silicon wafers. J. Appl. Phys. 52, 879-884 (1981).

31. Stesmans, A. \& Afanas'ev, V. V. Electron spin resonance features of interface defects in thermal (100)Si/SiO 2 . J. Appl. Phys. 83, 2449-2457 (1998).

32. O'Brien, P. G. et al. Photomethanation of gaseous $\mathrm{CO}_{2}$ over Ru/Silicon nanowire catalysts with visible and near-infrared photons. Adv. Sci 1, 1400001 (2014).

33. Hong, C., Lee, J., Zheng, H., Hong, S.-S. \& Lee, C. Porous silicon nanoparticles for cancer photothermotherapy. Nanoscale Res. Lett. 6, 1-8 (2011).

34. Han, L., Zeman, M. \& Smets, A. H. M. Raman study of laser-induced heating effects in free-standing silicon nanocrystals. Nanoscale 7, 8389-8397 (2015).

35. Regli, S., Kelly, J. A., Shukaliak, A. M. \& Veinot, J. G. C. Photothermal response of photoluminescent silicon nanocrystals. J. Phys. Chem. Lett. 3, 1793-1797 (2012).

36. Hessel, C. M., Henderson, E. J. \& Veinot, J. G. C. Hydrogen silsesquioxane: a molecular precursor for nanocrystalline $\mathrm{Si}-\mathrm{SiO}_{2}$ composites and freestanding hydride-surface-terminated silicon nanoparticles. Chem. Mater. 18, 6139-6146 (2006).

37. Kovalev, D., Gross, E., Diener, J., Timoshenko, V. Y. \& Fujii, M. Photodegradation of porous silicon induced by photogenerated singlet oxygen molecules. Appl. Phys. Lett. 85, 3590-3592 (2004).

38. Borrero-González, L. J. et al. The role of quantum confinement and crystalline structure on excitonic lifetimes in silicon nanoclusters. J. Appl. Phys. 108, 013105 (2010).

39. Kang, Z., Liu, Y. \& Lee, S.-T. Small-sized silicon nanoparticles: new nanolights and nanocatalysts. Nanoscale 3, 777-791 (2011).

40. Gardner, R. A. The kinetics of silica reduction in hydrogen. J. Solid State Chem. 9, 336-344 (1974).

41. Luca, O. R. \& Fenwick, A. Q. Organic reactions for the electrochemical and photochemical production of chemical fuels from $\mathrm{CO}_{2}$-the reduction chemistry of carboxylic acids and derivatives as bent $\mathrm{CO}_{2}$ surrogates. J. Photochem. Photobiol. B 152, 26-42 (2015).

42. Yu, Y. et al. Room temperature hydrosilylation of silicon nanocrystals with bifunctional terminal alkenes. Langmuir 29, 1533-1540 (2013).

43. Purkait, T. K. et al. Borane-catalyzed room-temperature hydrosilylation of alkenes/alkynes on silicon nanocrystalsurfaces. J. Am. Chem. Soc. 136, 17914-17917 (2014).

44. Michalak, D. J. et al. Nanopatterning $\mathrm{Si}(111)$ surfaces as a selective surface-chemistry route. Nat. Mater. 9, 266-271 (2010).

45. Inoue, T., Fujishima, A., Konishi, S. \& Honda, K. Photoelectrocatalytic reduction of carbon dioxide in aqueous suspensions of semiconductor powders. Nature 277, 637-638 (1979).

46. Hemminger, J. C., Carr, R. \& Somorjai, G. A. The photoassisted reaction of gaseous water and carbon dioxide adsorbed on the $\mathrm{SrTiO}_{3}(111)$ crystal face to form methane. Chem. Phys. Lett. 57, 100-104 (1978).

47. Habisreutinger, S. N., Schmidt-Mende, L. \& Stolarczyk, J. K. Photocatalytic reduction of $\mathrm{CO}_{2}$ on $\mathrm{TiO}_{2}$ and other semiconductors. Angew. Chem. Int. Ed. 52, 7372-7408 (2013).

48. Mao, J., Li, K. \& Peng, T. Recent advances in the photocatalytic $\mathrm{CO}_{2}$ reduction over semiconductors. Catal.Sci. Technol. 3, 2481-2498 (2013).

49. Hoch, L. B. et al. The rational design of a single-component photocatalyst for gas-phase $\mathrm{CO}_{2}$ reduction using both UV and visible light. Adv. Sci. 1, 1400013 (2014).

50. Sastre, F., Puga, A. V., Liu, L., Corma, A. \& García, H. Complete photocatalytic reduction of $\mathrm{CO}_{2}$ to methane by $\mathrm{H}_{2}$ under solar light irradiation. J. Am. Chem. Soc. 136, 6798-6801 (2014).

51. Styring, P. \& Armstrong, K. Assessing the potential of utilisation and storage strategies for post-combustion $\mathrm{CO}_{2}$ emissions reduction. Front. Energy Res. 3, 8 (2015).

52. Paolo, G. et al. QUANTUM ESPRESSO: a modular and open-source software project for quantum simulations of materials. J. Phys.: Condens. Matter 21, 395502 (2009).

53. Hartwigsen, C., Goedecker, S. \& Hutter, J. Relativistic separable dual-space Gaussian pseudopotentials from H to Rn. Phys. Rev. B 58, 3641-3662 (1998). 
54. Goedecker, S., Teter, M. \& Hutter, J. Separable dual-space Gaussian pseudopotentials. Phys. Rev. B 54, $1703-1710$ (1996).

55. Wagner, L. et al. The structure and stokes shift of hydrogenated silicon nanoclusters, Preprint at https://arxiv.org/abs/cond-mat/0403226 (2004).

56. Ahmed, M. E., Goss, J. P., Eyre, R. J., Briddon, P. R. \& Taylforth, M. A. Ab initio study of functionalized $1 \mathrm{~nm}$ silicon nanoparticles. J. Phys.: Conf. Ser. 245, 012046 (2010)

57. Chris, L. et al. SciNet: lessons learned from building a power-efficient top-20 system and data centre. J. Phys.: Conf. Ser. 256, 012026 (2010).

\section{Acknowledgements}

G.A.O. is a Government of Canada Research Chair in Materials Chemistry and Nanochemistry. Financial support for this work was provided by the Ontario Ministry of Research Innovation (MRI); Ministry of Economic Development, Employment and Infrastructure (MEDI); Ministry of the Environment and Climate Change; Connaught Innovation Fund; Connaught Global Challenge Fund; Natural Sciences and Engineering Research Council of Canada (NSERC). C.Q., W.S. thank the Connaught Foundation for graduate scholarships to support their doctoral research and L.H. expresses his gratitude to NSERC for a Banting post-doctoral fellowship. L.H. also acknowledges the support from National Basic Research Program of China (grant no. 2012CB932400) and the Major Research Plan of the National Natural Science Foundation of China (grant no. 91333208). Technical help with SEM from Yuchan Dong is deeply appreciated. We thank the Ontario Centre for the Characterization of Advanced Materials (OCCAM) for access to state-of-theart surface analytical equipment. C.V.S. gratefully acknowledges SciNet ${ }^{57}$ and Calcul Quebec consortia under the auspices of Compute Canada for computational resources.

\section{Author contributions}

W.S., C.Q., L.H. and G.A.O. conceived and designed the experiments. W.S. and C.Q. carried out the synthesis of the materials and performed materials characterizations.
L.H., A.P.Y.W., J.J., P.G.O.'B. and T.E.W. contributed to the photothermal gas-phase testing. K.K.G. and C.V.S. performed the DFT simulation. L.M.R. conducted the gas adsorption experiments. A.A.J. performed the XPS test. A.S.H helped evaluate the photothermal effect of Si. C.A.M. and G.A.O. funded and supervised the construction of the gas-phase reactor system. L.H. and G.A.O. supervised the project. W.S., C.Q.,

L.H. and G.A.O. wrote the paper. All the authors discussed the results and commented on the manuscript.

\section{Additional information}

Supplementary Information accompanies this paper at http://www.nature.com/ naturecommunications

Competing financial interests: The authors declare no competing financial interests.

Reprints and permission information is available online at http://npg.nature.com/ reprintsandpermissions/

How to cite this article: Sun, W. et al. Heterogeneous reduction of carbon dioxide by hydride-terminated silicon nanocrystals. Nat. Commun. 7:12553 doi: $10.1038 /$ ncomms12553 (2016).

\section{(c) (i)}

This work is licensed under a Creative Commons Attribution 4.0 International License. The images or other third party material in this article are included in the article's Creative Commons license, unless indicated otherwise in the credit line; if the material is not included under the Creative Commons license, users will need to obtain permission from the license holder to reproduce the material. To view a copy of this license, visit http://creativecommons.org/licenses/by/4.0/

(C) The Author(s) 2016 